\title{
Completion of Chronic Hepatitis C Virus Treatment in Interferon- Induced Major Depressive Disorder with Psychotic Features
}

\author{
Susie H. Park \\ Assistant Professor of Clinical Pharmacy, Titus Family Department of Clinical Pharmacy and Pharmaceutical Economics \& Policy, University of \\ Southern California, School of Pharmacy, Los Angeles, CA, USA
}

Interferon (IFN)-associated psychiatric disorders can be managed without interruption to hepatitis C virus (HCV) treatment. The limited number of cases in the literature reporting psychotic depression as an adverse drug reaction to IFN resulted in discontinuation of $\mathrm{HCV}$ therapy. The author reports a case of a 49 year-old man with chronic HCV genotype 1a treated with pegylated interferon-alpha and ribavirin developing major depressive disorder with psychotic features. The patient was successfully treated with both an antidepressant and antipsychotic for this suspected IFN-associated adverse drug effect while continuing 12 months of uninterrupted HCV treatment and subsequently achieving sustained hepatitis $\mathrm{C}$ virological response. Although IFN can cause distressing psychiatric disturbances, appropriate treatment with psychotropic agents and careful monitoring allows patients to be maintained on a full course of HCV treatment.

Psychiatry Investig 2011;8:381-383

Key Words Chronic hepatitis C virus, Pegylated interferon-alpha, Psychotic depression, Major depressive disorder, Psychosis, Antipsychotic.

\section{INTRODUCTION}

Standard pharmacologic treatment for chronic hepatitis C virus (HCV) infection for a disease that afflicts more than 170 million people worldwide ${ }^{1}$ is the antiviral combination of pegylated interferon (IFN) and ribavirin (RBV). ${ }^{2}$ IFN treatment is associated with psychiatric adverse drug reactions ${ }^{3}$ such as major depressive disorder, ${ }^{4,5}$ mania, ${ }^{6}$ psychosis $^{7-9}$ and suicidal ideation. ${ }^{10}$ Depending on its severity, discontinuation of IFN may be warranted. ${ }^{7}$ If monitored closely and managed carefully, however, patients with HCV can be placed on psychotropic medications to treat depressed mood, irritability, and even auditory and visual hallucinations, whereby sustaining HCV treatment. ${ }^{9}$ In the following report, an $\mathrm{HCV}$-infected patient was treated with a full course of IFN and RBV while being as-

Received: April 2, 2011 Revised: July 27, 2011

Accepted: August 1, 2011 Available online: November 14, 2011

$\triangle$ Correspondence: Susie H. Park, PharmD, BCPP, FCSHP

Assistant Professor of Clinical Pharmacy, Titus Family Department of Clinical Pharmacy and Pharmaceutical Economics \& Policy, University of Southern California, School of Pharmacy, 1985 Zonal Avenue, Los Angeles, CA 90033, USA

Tel: +1-323-442-1675, Fax: +1-323-442-1681, E-mail: susiepar@usc.edu

(a) This is an Open Access article distributed under the terms of the Creative Commons Attribution Non-Commercial License (http://creativecommons.org/licenses/by$\mathrm{nc} / 3.0$ ) which permits unrestricted non-commercial use, distribution, and reproduction in any medium, provided the original work is properly cited. sessed regularly and adequately maintained on an antidepressant and antipsychotic for emergent psychotic depression. The patient eventually achieved a sustained virological response (SVR) with a full course of uninterrupted HCV treatment due to control of psychiatric symptoms.

\section{CASE}

A 49 year-old man diagnosed with chronic HCV genotype la was screened at the hepatitis $\mathrm{C}$ clinic. He was been infected approximately 30 years ago from intravenous drug use which stopped 18 years ago. After starting a 48-week course of HCV therapy he progressively developed major depressive disorder (MDD) with psychotic features requiring pharmacologic intervention.

Laboratory findings prior to IFN initiation included an HCV RNA viral load of 2,950,000 copies/mL. Hepatitis B surface antigen and HIV tests were both negative. Hematological findings were unremarkable and baseline TSH was $1.70 \mathrm{uIU/}$ $\mathrm{mL}$ (normal= $0.5-3.50$ ). Routine depression monitoring on clinic visit 1 revealed a baseline Personal Health Questionnaire-9 items ${ }^{11}$ (PHQ-9) score of 3, indicating decreased energy experienced almost daily. Table 1 summarizes depressive symptoms over the course of IFN treatment, which 
Table 1. 48 weeks of hepatitis C virus treatment and co-occurring events

\begin{tabular}{|c|c|c|c|}
\hline Time (weeks) & Target symptoms/Response & PHQ-9 score & Psychotropic progression \\
\hline 0 & Decreased energy & 3 & None \\
\hline 7 & $\begin{array}{l}\text { Decreased energy, depressed mood, impaired sleep, anhedonia, } \\
\text { worthlessness, mild anxiety, poor concentration, passive suicidal } \\
\text { ideation }\end{array}$ & 19 & $\begin{array}{l}\text { Citalopram } 10 \mathrm{mg} \times 3 \text { days, then increased to } \\
20 \mathrm{mg} / \text { day thereafter }\end{array}$ \\
\hline 12 & $\begin{array}{l}\text { Decreased energy, depressed mood, improved sleep, anhedonia, } \\
\text { poor concentration, less suicidal ideation }\end{array}$ & 11 & Increased citalopram to $40 \mathrm{mg} /$ day \\
\hline 21 & $\begin{array}{l}\text { Decreased energy, improved mood but still depressed, increased } \\
\text { interest in usual daily activities }\end{array}$ & 10 & Increased citalopram to $60 \mathrm{mg} /$ day \\
\hline 29 & Euthymic mood, no longer passive suicidal thinking & NA & Continue citalopram $60 \mathrm{mg} /$ day \\
\hline $33^{*}$ & $\begin{array}{l}\text { Suicidal ideation, severely impaired concentration, increased } \\
\text { anxiety, active auditory and visual hallucinations }\end{array}$ & 25 & $\begin{array}{l}\text { Was unknowingly given a refill for only } \\
\text { citalopram } 40 \mathrm{mg} / \text { day by a different clinician; } \\
\text { increased citalopram to } 60 \mathrm{mg} / \text { day today }\end{array}$ \\
\hline $34^{*}$ & $\begin{array}{l}\text { Less suicidal, moderate anxiety, some residual auditory and } \\
\text { visual hallucinations; mild persistent paranoia }\end{array}$ & 19 & $\begin{array}{l}\text { Start aripiprazole } 5 \mathrm{mg} \times 7 \text { days then increases } \\
\text { to } 10 \mathrm{mg} \text { /day thereafter; Continue citalopram } \\
60 \mathrm{mg} / \text { day }\end{array}$ \\
\hline 38 & Euthymic mood, fewer hallucinations; mild persistent paranoia & NA & $\begin{array}{l}\text { Increased aripiprazole } 15 \mathrm{mg} / \text { day; } \\
\text { Continue citalopram } 60 \mathrm{mg} / \text { day }\end{array}$ \\
\hline 48 & Euthymic mood, low energy; no paranoia & 7 & $\begin{array}{l}\text { Decreased aripiprazole } 10 \mathrm{mg} / \text { day; } \\
\text { Continue citalopram } 60 \mathrm{mg} / \text { day }\end{array}$ \\
\hline
\end{tabular}

Maximum score on the Personal Health Questionnaire (PHQ-9) is 27. * called patient at home twice between weeks 33 and 34 . NA: not available

demonstrates a significant increase in the depression score when HCV treatment first began. Pegylated interferon-alpha 180 micrograms once weekly and ribavirin $600 \mathrm{mg}$ twice daily were started. Approximately seven weeks after initiation, the patient began reporting feelings of depressed mood, impaired sleep, poor concentration, and passive suicidal ideation (PHQ9 score of 19). He insisted, however, that he would never take his own life due to personal religious convictions.

He was counseled about the possibility that his depression could get worse without an antidepressant and subsequently his HCV treatment may have to be discontinued. He therefore agreed to start citalopram. When the dose was eventually increased to $60 \mathrm{mg} /$ day, his mood remained mildly depressed but he no longer reported anhedonia. He requested to be maintained on this maximum dose through week 29.

When the patient returned to clinic for routine follow-up at week 33, it was discovered that he was inadvertently taking a lower daily antidepressant dose of $40 \mathrm{mg}$ for the past two and a half weeks. He started to report severe worsening of mood, passive suicidal ideation, impaired concentration, un-intrusive auditory and visual hallucinations, and mild paranoia around people he was unfamiliar with. Citalopram was immediately increased back to $60 \mathrm{mg} /$ day. The patient denied suicidality and the interdisciplinary team decided that hospitalization was not required. The clinician corroborated the report with the patient's sister and agreed to follow the patient more closely with home telephone calls. The patient agreed to start an antipsychotic and was maintained on aripiprazole 15 $\mathrm{mg}$ /day. One week later, suicidal thinking was minimal and hallucinations were less bothersome but still present. Mild paranoid thinking persisted for 7 additional weeks until finally subsiding.

The patient was able to complete the full 48-week course of IFN and RBV indicated for HCV genotype $1 \mathrm{~b}$ without a decrease in IFN dose, interruption in therapy, or further complications. When added to the HCV medications, both citalopram and aripiprazole were well-tolerated. The PHQ-9 score by the end of treatment was 7, indicating that he had positive treatment response to the antidepressant. Although aripiprazole was discontinued, citalopram $40 \mathrm{mg} /$ day for an additional 6 months with a corresponding PHQ-9 score of 4 was continued. At the 1-year follow-up visit, the patient maintained an SVR and no longer required either psychotropic medication.

\section{DISCUSSION}

IFN-induced psychiatric complications are a common reason for HCV treatment discontinuation. There are few reports describing patients who develop symptoms of clinical depression with psychosis occurring after the initiation of IFN and RBV therapy. ${ }^{9,12,13} \mathrm{~A}$ case of MDD with psychotic features induced by IFN in a polydrug user describes the patient requir- 
ing discontinuation of HCV treatment and the addition of an antidepressant and antipsychotic agent. ${ }^{12}$ In other instances, patients do not require cessation of HCV treatment when such adverse psychiatric events occur as long as a psychotropic agent is implemented..$^{14}$ If feasible, concomitant treatment with appropriate psychotropics should be initiated with continuous HCV treatment. Further studies are needed to address the appropriateness of stopping such agents relative to the end of $\mathrm{HCV}$ treatment.

Possible neurochemical mechanisms of IFN-induced psychopathology include diminished serotonergic neurotransmission. ${ }^{15}$ Hepatic tryptophan dioxygenase degrades tryptophan, the precursor of serotonin. This suggests that as a class of polypeptide cytokines, IFNs possess anti-serotonergic effects and may suppress serotonin synthesis. Further investigation is required to describe depression provocation by IFN.

Depressive symptoms, when inadequately controlled, can lead to secondary psychosis. The psychotic features in this patient were mood-congruent to the depression. Once the depression eventually improved, the psychotic symptoms began remitting. Careful observation was required to ensure that he would not act upon the command auditory hallucinations and paranoia and subsequently harm himself. This required additional close contact with the patient's sister in order to ensure completion of HCV treatment even in the presence of co-morbid psychiatric complications caused by the antiviral medications.

Liver function tests monitoring continued and no complications or adverse events were observed with concomitant use of aripiprazole and citalopram. Once-daily aripiprazole was chosen because the patient did not wish to be overly sedated, as he was already feeling fatigue from IFN. A careful balance between minimizing psychotropic polypharmacy and adequately managing substance-induced mood disorder should exist. This is the first reported case of aripiprazole used in the management of IFN-induced psychotic depression where HCV treatment completion resulted in SVR. There is a report on the use of aripiprazole $10 \mathrm{mg} /$ day in a patient who developed IFN-induced psychosis with no noted depression who had to prematurely discontinue HCV treatments. ${ }^{16}$

Clinicians should work together to manage adverse psychiatric drug reactions in order to sustain $\mathrm{HCV}$-infected individuals on necessary antiviral regimens with the goal of achieving SVR. Early detection and treatment of psychiatric complications induced by IFN can spare HCV treatment. Careful psychiatric symptom assessment of patients using IFN is required in all patients at baseline and as HCV treatment pro- gresses. Immediate identification of serious adverse effects and intervention with appropriate psychotropic treatments allows patients to be managed for psychiatric side effects while being maintained successfully on the difficult treatment regimen for $\mathrm{HCV}$.

\section{REFERENCES}

1. WHO. Global surveillance and control of hepatitis C. Report of a WHO Consultation organized in collaboration with the Viral Hepatitis Prevention Board, Antwerp, Belgium. J Viral Hepat 1999;6:35-47.

2. Fried MW, Shiffman ML, Reddy KR, Smith C, Marinos G, Gonçales FL Jr, et al. Peginterferon alfa-2a plus ribavirin for chronic hepatitis $\mathrm{C}$ virus infection. N Engl J Med 2002;347:975-982.

3. Renault PF, Hoofnagle JH, Park Y, Mullen KD, Peters M, Jones DB, et al. Psychiatric complications of long-term interferon alpha therapy. Arch Intern Med 1987;147:1577-1580.

4. McHutchison JG, Gordon SC, Schiff ER, Shiffman ML, Lee WM, Rustgi $\mathrm{VK}$, et al. Interferon alfa-2b alone or in combination with ribavirin as initial treatment for chronic hepatitis C. Hepatitis Interventional Therapy Group. N Engl J Med 1998;339:1485-1492.

5. Martin-Santos R, Diez-Quevedo C, Castellvi P, Navinés R, Miquel M, Masnou H, et al. De novo depression and anxiety disorders and influence on adherence during peginterferon-alpfa-2a and ribavirin treatment in patients with hepatitis C. Aliment Pharmacol Ther 2008;27: 257-265.

6. Onyike CU, Bonner JO, Lyketsos CG, Treisman GJ. Mania during treatment of chronic hepatitis $\mathrm{C}$ with pegylated interferon and ribavirin. Am J Psychiatry 2004;161:429-435.

7. Garcia-Parés G, Domenech C, Gil M. Psychosis induced by interferonalpha. Psychosomatics 2002;43:428-429.

8. Tamam L, Yerdelen D, Ozpoyraz N. Psychosis associated with interferon alfa therapy for chronic hepatitis B. Ann Pharmacother 2003;37: 384-387.

9. Hoffman RG, Cohen MA, Alfonso CA, Weiss JJ, Jones S, Keller M, et al. Treatment of interferon-induced psychosis in patients with comorbid hepatitis C and HIV. Psychosomatics 2003;44:417-420.

10. Ademmer K, Beutel M, Bretzel R, Clemens J, Reimer C. Suicidal ideation with IFN-alpha and ribavirin in a patient with hepatitis C. Psychosomatics 2001;42:365-367.

11. Spitzer RL, Kroenke K, Williams JB. Validation and utility of a self-report version of PRIME-MD: the PHQ primary care study. Primary Care Evaluation of Mental Disorders. Patient Health Questionnaire. JAMA 1999;282:1737-1744.

12. Kalyoncu OA, Tan D, Mirsal H, Pektas O, Beyazyurek M. Major depressive disorder with psychotic features induced by interferon-alpha treatment for hepatitis $\mathrm{C}$ in a polydrug abuser. J Psychopharmacol 2005; 19:102-105.

13. Sockalingam S, Balderson K. Major depressive episode with psychotic features induced by pegylated interferon-alpha- $2 \mathrm{~b}$ and ribavirin treatment. Int Clin Psychopharmacol 2005;20:289-290.

14. Quarantini LC, Cruz SC, Bastista-Neves SC, Paraná R, Miranda-Scippa $\hat{A}$, Bressan RA. Psychosis during peginterferon-alpha 2a and ribavirin therapy: case report. Braz J Infect Dis 2006;10:406-407.

15. Menkes DB, MacDonald JA. Interferons, serotonin, and neurotoxicity. Psychol Med 2000;30:259-268.

16. Silverman BC, Kim AY, Freudenreich O. Interferon-induced psychosis as a "psychiatric contraindication" to hepatitis $C$ treatment: a review and case-based discussion. Psychosomatics 2010;51:1-7. 